\title{
Perspectives of teachers on causes of children's maladaptive behaviour in the upper primary school level: A case of Hhohho Region, Eswatini
}

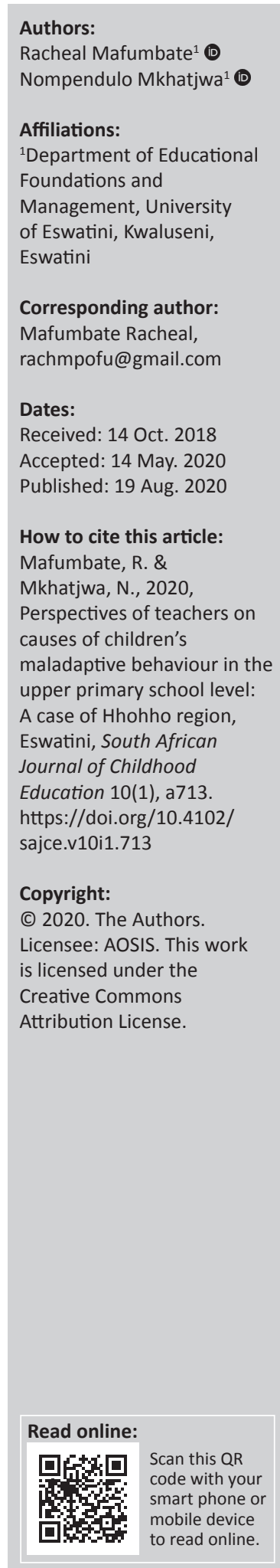

Background: The background which led to the researchers embarking in this research study was that they had noticed that teachers in schools in Eswatini, though they are always trying to ensure good behaviour of learners through positive discipline, maladaptive behaviour is still on the rise in most schools. This status has resulted in compromised teaching and learning since most of the time is now spent in trying to deal with maladaptive behaviour issues. If the behaviour of learners is not dealt with, they face a greater risk of becoming violent and chronic juvenile offenders.

Aim: The aim of the study was to explore the factors contributing to children's maladaptive behaviours in the upper primary school level.

Setting: The study was conducted in the Hhohho region in Eswatini.

Methods: The study employed a qualitative research design and in-depth interviews and focus group discussions were used as data gathering instruments. Note taking and audio recordings were used to ensure that details the discussions were captured.

Results: The study revealed that a lack of proper parenting skills is a major factor, and that family dysfunctionality, family socioeconomic status as well as peer influence being contributors to maladaptive behaviour among children in Hhohho region.

Conclusion: Based on the literature and findings in this study, it is evident that maladaptive behaviour among children in primary schools is persistent and a serious problem worldwide. This study revealed that currently there are no intervention strategies in the school to enhance proper behaviour among learners. Teachers also struggle to implement positive discipline because they lack the know-how.

Keywords: home factors; school factors; maladaptive behaviour; children.

\section{Background of the study}

The readiness or willingness of an individual to demonstrate decent and good conduct, respect for authority, high sense of responsibility, love for orderliness, eagerness to discharge duties with promptitude and efficiency makes the individual 'acceptable' (Kwaja \& Mormah 2011). When an individual fails to reflect these characteristics, maladaptive behaviour occurs. Any behaviour tagged maladaptive runs contrary to the generally acceptable patterns of behaviour for the age and the environment of the individual and this behaviour negatively affects that individual and the people around him or her (Ughamadu \& Enueme 2002).

In every society there are norms and values to which each member of a particular community is expected to adhere. Conformity to such norms and values brings about cohesion amongst the members of the particular community (Mweemba 2011). A school is said to be a community within a larger community. Schools in Eswatini are always trying to embark on orderliness through positive discipline (Tungata 2006). However, maladaptive behaviour is on the rise in most schools in Eswatini (Dlamini, 2013; Mhlongo 2005). This state of affairs worries teachers, parents and the society at large as schools now spend more time dealing with maladaptive behaviour issues instead of imparting knowledge to the young generation which is tomorrow's future to ensure that they realise their full potential. Furthermore, children who are showing this behaviour face a greater risk of becoming violent and chronic juvenile offenders if nothing is done to correct their behaviour (Kwaja \& Mormah 2011).

Eswatini like any other developing country endeavours to protect its children, as clearly indicated in its Constitution and national policy (Mavundla et al. 2015). Furthermore, Eswatini is a signatory to the 
Convention on the Rights of the Child, which compels it to pass laws and take social, educational and administrative measures to protect children from all forms of physical and mental violence, injury or abuse, neglect or negligent treatment, and maltreatment and abuse (Tungata 2006). Eswatini has also ratified the United Nations Charter on the Rights of the Child (CRC) in 1995. In addition, it has made a reservation to the CRC relating to the progressive implementation of children's right to education. All this has been done to ensure that children realise their full potential and are well protected.

\section{Statement of the problem}

The Swazi government is doing everything possible to protect its children and has clearly articulated this in the national policy documents (Mavundla et al. 2015). Eswatini has ratified major child rights instruments such as the Convention on the Rights of the Child, ratified on 06 October 1995, and the African Charter on the Rights and Welfare of Children, signed on 29 June 1999. The country has a progressive national constitution which, in Article 29, sets out a number of rights that specifically apply to children, including in relation to work; abuse, torture or other cruel inhuman or degrading treatment or punishment; the right to be properly cared for by parents or another lawful authority; discrimination on the basis of parents' marital status; a duty of children to respect their parents; the right to education; and Parliament's duty to enact laws for the protection of children (World Vision 2018).

Furthermore, Article 20 (also known as the Equality Clause) of the Constitution provides for equality before the law in all spheres of political, social and cultural life and nondiscrimination as related to gender, race, colour, ethnic origin, tribe, birth, creed or religion, or social or economic standing, political opinion, age and disability. Eswatini has a dual legal system, where the general law (comprising Roman Dutch common law and Statute) and Swazi customary law (uncodified) operate side by side and are equal in legitimacy and authority. Often this results in conflicts of laws, leading to numerous violations of children's and women's rights. Despite all these efforts, maladaptive behaviour is on the rise in most schools in Eswatini (Dlamini 2013; Mhlongo 2005). Maladaptive behaviour amongst children, especially in the upper primary school of education, is now a universal challenge in most schools in the world in general (Amato \& Cheadle 2008) and in schools in Eswatini in particular. Children exposed to maladaptive behaviour may develop mental health problems, impacting their ability to develop appropriate social emotional skills. Several research studies have revealed that limited development of social emotional skills has been associated with poor performance in schools (Dlamini 2013; Mwirichia 2013; Michubu, 2013). Hence, this study sought to find answers to the following question: which home and school factors contribute to children's maladaptive behaviour in the upper primary school level in the Hhohho region of Eswatini?

\section{Objectives}

The study sought to explore the home and school factors that contribute to children's maladaptive behaviour in the selected upper primary school in Hhohho region.

\section{Theoretical framework}

This study is underpinned by an integrative framework of Bandura's (1977) social learning theory and Freud's psychosocial theory. Both theories argue that the early childhood experiences affect an individual's future life. Thus, both theorists suggest that behaviour is determined primarily by the people around an individual. Bandura's (1977) social learning theory posits that most human behaviour is learnt through observation as well as through modelling. From observing others, an individual forms an idea of how new behaviours are performed and, on later occasion, this coded information serves as a guide for action. Children attempt to internalise the conduct from other people and acquire behaviour patterns that are similar to others.

On the other hand, Freud maintains that behaviour is determined by prior mental events in one's life (Sarason 2005). According to Freud, personality develops during childhood and is critically shaped through a series of five psychosexual stages, which he called his psychosexual theory of development. During each stage, a child is presented with a conflict between biological drives and social expectations; successful navigation of these internal conflicts will lead to mastery of each developmental stage, and ultimately to a fully mature personality.

Furthermore, Sarason (2005) argues that the behavioural perspective focuses on behaviour as a response to stimuli in the environment of the organism. These two theories emphasise the central role of the society in influencing one's behaviour. They also provide insights on the impact which society and other people have on the development of a child's personality (Mcleod 2011). The implication of the theories is that the social surroundings of a child contribute immensely to personality development because the people in the social environment of a child are the ones he or she imitates and identifies with. Children's behaviour can be said to be a mirror image of the society. In this regard, the maladaptive behaviour of a child can be understood largely through examining the child's social environment, the significant others and the society at large. As children observe others, they might incorporate their goals and values with their own behaviours in an effort to feel connected or identified with those individuals around them. According to Mcleod (2011), the impact can either be positive or negative based on the person whom the child chooses to emulate.

The researchers applied this integrative lens in order to gain an in-depth understanding of perspectives of teachers on causes of maladaptive behaviours. Furthermore, the researchers were able to identify gaps in the literature, and provide suggestions for future research on causes of 
maladaptive behaviour amongst learners in general and in upper primary school level in particular. Bandura's (1977) theory suggested that the social environment is an important aspect in understanding the environmental factors associated with maladaptive behaviour. These theories were very useful in exploring different aspects of children's behaviour in terms of their social environment, such as general parenting, the role of peers in relation to how this impacts their behaviour and the general neighbourhood in which they live. Rhee and Waldman (2009) observed that social environment is the most significant factor influencing the behaviour of children and adolescents. Both theories offer an insight into the possible factors contributing to maladaptive behaviour and shed some light on the possible role of inadequate learning experiences on children's maladaptive behaviour.

\section{Definition of maladaptive behaviour}

In this study, maladaptive behaviours will be conceptually considered as those actions that stop an individual from adapting to new circumstances, thereby displaying the following: passive aggressiveness, avoidance, withdrawal, self-harm, anger, substance use as well as day dreaming (Eyman \& Call 1977).

\section{Research methodology}

This study employed a qualitative research approach, involving interpreting things in a natural setting in an attempt to make sense of or interpret phenomena in terms of the meaning people bring to them (Creswell 2014; Denzin \& Lincoln 2008). Creswell (2014) also stated that a qualitative enquiry is a process of understanding a social or human problem based on building a complex holistic picture, formed with words, and reporting detailed views of informants and conducted in natural setting. It is an inquiry process of understanding based on distinct methodological traditions that explore a human problem (Morehouse 2011). The interpretative paradigm was best suitable for this study as the purpose of the researchers was to get insight into and indepth information about the perspectives of teachers on causes of maladaptive behaviour of learners in the upper primary school level. This approach was found to be most ideal for this study as it enabled the researchers to interact with the participants of the study, thereby obtaining relevant data pertaining to the topic under study, through exploring the influence of parenting skills and peer pressure on children's maladaptive behaviour (Merriam 2009). Oost (2003) argues that any research should perform six functions, namely, describing, comparing, defining, explaining, evaluating and designing. The choice of this design enabled the researchers to establish an in-depth understanding of the perspectives of teachers on children's maladaptive behaviour in the upper primary school level.

Qualitative research engages the researcher with interviews, conversations, photographs, recordings and memos which make the world visible as it involves studying objects in their natural setting (Denzin \& Lincoln 2008). This eventually brings a clear picture and a clear meaning to people of what is happening on the ground. The researchers explored and voice recorded what was being said by teachers to ensure that every word said was captured. The qualitative research approach tends to be an ongoing (non-linear) process, implying that data collection, processing, analysis and reporting are intertwined, and not merely a number of successive steps (Florian 2006). In qualitative studies, researchers often find it advisable and necessary to go back to the original field notes and verify conclusions, or to the participants to collect additional data and to verify them, or to solicit feedback from participants consulted in the research (Denzin \& Lincolin 2011). This implies that, upon completion of this study, the researchers will conduct a workshop in order to give participants feedback on the research findings.

This study adopted an ethnographic research design because the researchers were studying learners in a naturally occurring setting in order to capture their social meanings and ordinary activities whilst in a particular social system (Brewer 2006; Creswell 2007; De Vos, Strydom, Fouche \& Delport 2012). A significant amount of time was spent in the field whilst studying the interactional patterns of learners. The researchers' aim was to come up with a thick descriptive account of the social life of learners in this school (Creswell et al. 2011). Spencer, Ritchie, Lewis and Dillion (2003) identified three overlapping areas in a research design, namely: philosophy, which covers issues of ontology, that is, theories of what the world is; epistemology which deals with theories of how the world can be interpreted; and methodologies which deal with the methods which encompasses issues on sets of techniques for interpreting the world (Babbie 2013). Logistics and practice relate to selecting the study area, proposal development, budgeting and planning for ethical research. These were also important in this study.

Although qualitative research is often criticised for being dependent on the researcher's skills and is time-consuming, it is effective for studying subtle nuances in attitudes and behaviours and for examining social processes. The strength of the approach lies in the depth of understanding the phenomena under study. This design also allows the researcher to gain detailed and rich data in the form of comprehensive written descriptions and visual evidence. Therefore, a qualitative approach was the most appropriate because of its focus on quality information gathered rather than the amount of data. By gathering qualitative data from a natural setting, the findings of the study lead to understanding and interpreting the experiences of participants in the society (Creswell 2014).

\section{Data collection procedures}

An introductory letter was sought from the university and presented to the director in the Ministry of Education and Training to seek permission to conduct the study in school A. An initial visit was made to the school as introduction after 
the researchers were granted permission to conduct the study there. The second visit was to make arrangements in terms of time with the deputies and the class teachers and to create rapport with them. The third visit was for making arrangements in terms of time, and participants also signed consent forms. The fourth visit was for the focus group discussions. In-depth interviews were conducted on the fifth and sixth visits. Note-taking and audio recording were conducted for all interviews.

\section{Data analysis procedure}

Data analysis is a strategy used to examine the data for meaningful themes, issues or variables to discover how these are patterned and to attempt to explain such patterns (McMillan \& Schumacher 2010). Qualitative data from both in-depth and focus group discussion interviews were analysed using content analysis as suggested by Henning, Van Rensburg and Smit (2004). The inductive process was used to analyse information from items which were combined to form descriptions, recurring themes and results. Similar themes were linked together. This was followed by the translation and interpretation of similar themes to create concepts as outlined by Henning et al. (2004). Firstly, the researcher segmented units of meaning in one or more sentences. Secondly, the researcher labelled units (coding) of meaning in more than a single word. Related codes were grouped and categorised in the third stage. In the fourth stage, themes were identified from the categories.

A running summary was drawn from the field notes. Unstructured items were analysed manually along major concepts and themes and the results were presented in a table. Conclusions drawn from the analysed data led to recommendations and suggestions regarding children's maladaptive behaviour in the primary schools in Eswatini.

\section{Findings and discussions}

The discussions of the findings are based on the following two main themes:

- inadequate parenting skills, family dysfunctionality or family socio-economic status

- peer influence as a contributory factor to lack of discipline in schools.

\section{Home factors}

The study established home environment factors as the main source of influencing maladaptive behaviour amongst learners. Participants mentioned that parents are the first people with whom a child interacts in his or her environment and who the child imitates. Furthermore, this study noted that a healthy home environment where parents show love, care, counselling, guidance and tenderness for the children influences the children's personality and behaviour positively, whilst a toxic home environment where children see hatred, quarrel, bitterness, hostility and violence influences the children in a negative way.
The most common home factors perceived as the greatest contributor to children's maladaptive behaviour included parenting style, family socio-economic status and home dysfunctionality. Above all, the study discovered that a lack of parenting skills is a major factor to maladaptive behaviour amongst children in the Hhohho region. Participants noted with concern that parents no longer seemed to invest their time and energy into preventing behavioural problems at an early stage of the child. They felt that children lacked adequate guidance in this regard. Furthermore, according to the participants, children need discipline and the establishment of boundaries and routines. Below are some verbal quotes that are an example of what the participants said during in-depth interviews:

'Inconsistent parenting style swinging from excessive punishment to excessive leniency is capable of participating in maladaptive behaviour.' (Participant 2, 49 years, male deputy head-teacher)

These findings are in agreement with that of Mburugu and Adams (2001) who also pointed out that some parents are significantly engaged in a variety of activities and seem to have little or no time to supervise their children, to role model or offer them social content-based education to compensate for the inadequacy of the academic education they have which does not teach them much on the societal norms and values. The findings of this study also concur with that of Binh (2012) who also observed that in modern times, fathers tend to use reasons such as their attention to their careers, promotion or earning a living for not spending time with their children. Yet parents in the olden days would take their parenting responsibility seriously to ensure that children are equipped with acceptable behaviour as members of the society.

This study noted that a home dysfunctionality is another factor contributing to children's maladaptive behaviour in the Hhohho region. Participants believe that divorce or separation causes maladaptive behaviours amongst children. Furthermore, it was noted that single parenting style is also contributing to children's maladaptive behaviour. The participants voiced their views that in most cases it seems that the youth are dissatisfied with the decisions taken by their parents to either divorce or separate and so they express their disapproval through rebellious behaviours such as stealing, running away from home or using illegal drugs. Participant in the focus group discussions said:

'When we try to dig deep as to why some of the children are involved in maladaptive behaviour, they simple state that they have committed the offence just to get back to their parents.' (Participant 7, 38 years, grade 7 female teacher, FGDS)

These findings concur with the findings of Amato and Cheadle (2008) who conducted a study in Pennsylvania on parental divorce, marital conflict and children's behavioural problems and found that a standard family environment model assumes that marital conflicts and divorce increase the risk of children's behavioural problems. The findings of this study seem to be in agreement with the findings of Dlamini 
(2013) on factors responsible for maladaptive behaviour in the secondary schools, which revealed that home problems often result in a child behaving in an unacceptable way, for instance, being aggressive or bullying other learners.

Furthermore, the findings of the current study are in line with that of Gasa (2009) who also observed that divorce is a major source of stress for the whole family including children. Furthermore, the findings of this study are in line with the findings of Anyanwu and Obiyo (2012), who established that broken and parental projections can enhance maladaptive behaviours. Further, Huston, Mcloyd and Coll (2008) established that children in economically deprived families, are likely to be at a higher risk of depression, low selfconfidence, peer conflict and conduct disorders. In their study, they also noted that, these children live with parents who are always moving from one place to another, resulting in their children shifting schools and neighbourhoods. This movement eventually impact negatively on children's emotional, social and academic wellness. Furthermore, Eyman and Call (1977) stated that maladaptive behaviour can start after a major life change, illness or traumatic event. It could also be a habit that an individual picked up at an early age.

The findings of the study indicated that children from poor homes lack some basic needs. The participants stated that poor parents are unable to satisfy all their needs. Hence, they sometimes resort to stealing, prostitution and selling illegal drugs. The learners themselves may even resort to drug abuse to try to escape the experience of deprivation. The participants further stated that some offenders are from human immunodeficiency virus and acquired immune deficiency syndrome (HIV and AIDS) pandemic-stricken families where no one is there to provide care for them at all. One participant in the focus group discussion said:

'Children nowadays are heads of families due to HIV/AIDS and due to that they find themselves being involved in unacceptable behaviours in order to meet their day-to-day needs. For example, young children being involved with sugar daddies to meet their monetary needs and some involved in stealing or selling of drug just to make cash to feed their young brothers and sisters.' (Participant 8, 42 years, grade 6 male teacher, FGDS)

The findings of this the study are in line with the findings of Kwaja and Mormah (2011) regarding adolescents' maladaptive behaviour in Nigerian secondary schools, which revealed that family socio-economic status has a huge impact on the behaviour of the child. Such children may not have access to a number of basic needs, which then leads to frustration, subsequently leading to some form of delinquency to avoid the discomfort. The study findings also concur with that of Huston (1994) who noted that poor children are at risk of developmental delays in intellectual development and school achievement. Furthermore, the current study findings are also in line with Huston (2003) who established that childhood poverty and its associated family and social conditions have deleterious effects on children's development.

\section{School factors}

The findings of the study indicated that the participants acknowledged the school as another powerful socialising centre which has the potential of influencing the child's behaviour in a negative or positive way. The participants revealed the following as possible factors contributing to children's maladaptive behaviour at school: peer influence and lack of discipline in schools. This is what some participants said during the in-depth interview and focus group discussions:

'School is a powerful socialising institution which plays a vital role in influencing one's behaviour; unfortunately the learners in the schools often fall in the trap of socialising with wrong friends which often make them to behave in a maladaptive manner. However, good friends may have a good influence.' (Participant 1, 52 years, female deputy interviewee)

'Peer group association exerts influence on the behaviour of a child. A child who belongs to a peer group whose members engage in anti-social activities such as under-age smoking, violence and alcoholism is most likely to imbibe these attitudes.' (Participant 4, 35 years, grade 6 female teacher, FGDS)

In this study, participants were of the view that some learners behave in maladaptive ways because of peer influence. According to the participants, it is a common occurrence for a learner to use illegal drugs, drink alcohol or become involved in sexual misconduct because his or her friends are doing so. These findings in this study concur with the findings of Mhlongo (2005) who found that $68 \%$ of the adolescents in Eswatini were involved in drug abuse because their peers at school had introduced them to drug abuse. According to Belle (2017), delinquent youth are more likely to be affiliated with delinquent friends compared to non-delinquent youth. Sullivan (2006) also agrees that peer pressure is the strongest predictor of delinquency compared to family factors. The findings of this study also concur with the findings of Kwaja and Mormah (2011), who conducted their study on managing adolescent's maladaptive behaviour in Nigerian secondary schools and found that adolescents sometimes follow the dictates of their peers. Furthermore, the study findings concur with that of Zatto and Hoglund (2019) who found that children who display high level of maladaptive tendencies are perceived to interact less positively with their teachers and other peers in their primary school level. Rubin and Clark (1983) also noted that such children displayed less mature and more disruptive tendencies in the class, and usually have poor academic results. Thus, being in line with Bandura's (1977) theory which suggests that the social environment is an important aspect in understanding the environmental factors associated with maladaptive behaviour.

The findings of the current study revealed that schools are faced with disciplinary problems ever since corporal punishment has been discouraged in schools by the Ministry of Education and Training in Eswatini. Furthermore, it was revealed that participants lack knowledge regarding how positive discipline can effectively curb unwanted behaviours in the school. In this discipline model, the teacher has to focus on reinforcing good behaviour and acknowledge the expected behaviour amongst 
learners. In this way, the teacher will be able to enhance positive discipline. Below are examples of quotes from some participants during the focus group discussions:

'The rate of maladaptive behaviour in schools is likely to escalate
because the government of Eswatini did not train us on how to
use positive discipline in replacing corporal punishment. We lack
an understanding on how to use the so-called "positive discipline"
effectively in disciplining learners. As a result, some teachers
nowadays only pay more attention to teaching learners other than
disciplining them even if they show unacceptable behaviours.'
(Participant 10, 56 years, grade 7 female teacher, FGDS) 'Our learners are fully aware that our hands are tied up now in terms of corporal punishment, which at least they were afraid of. Instead, we are expected to reward them for not engaging in wrong things and ignore any form of unwanted behaviour, how practical is that? The best thing is to turn a blind eye and let them behave anyhow.' (Participant 4, 35 years, grade 6 female teacher, FGDS)

The views of the participants in this study seem to be in line with Mtonga (2016) who affirmed that the step taken by the Republic of Zambia to abolish corporal punishment in all schools created serious disciplinary issues in Zambian schools. The study further revealed that after corporal punishment was abolished in Zambian schools, teachers were expected to use alternative modes which are non-corporal to instil positive behaviour despite the government not providing workshops for teachers to be equipped with guidance and counselling skills as an alternative. The view that ill-discipline in schools is because of the fact that corporal punishment has been abolished seems to be contradictory to the findings of Nakpodia (2012) who indicated that corporal punishment has no place in the education of children and that it perpetuates the cycle of abuse and has to be banned in schools.

\section{Conclusion}

Maladaptive behaviour amongst children in primary schools is a persistent and serious problem worldwide triggered by various issues. Based on the views of the participants in this study, home factors contributing to children's maladaptive behaviour include inadequate parenting styles, home dysfunctionality and family socio-economic status. It was also concluded that school factors that are contributing to children's maladaptive behaviour included peer influence and a lack of discipline. The study findings revealed that there are currently no intervention strategies in school A for learners to better manage their behaviours. Teachers also seem to struggle to implement positive discipline because they lack the know-how. The findings highlight the need for researchers to check whether other factors in the school may contribute to maladaptive behaviours, such as school environment and curriculum and pedagogy.

\section{Recommendations}

- The following are the recommendations of this study:

- The Ministry of Education and Training in Eswatini should consider training teachers in basic counselling skills to ensure cases of children's maladaptive behaviours are managed appropriately through the use of positive discipline.

- Eswatini may consider establishing a permanent government mechanism at national level for consulting on matters relating to policy development and implementation related to child protection with relevant non-governmental organisations and other stakeholders.

- Parliament may also consider establishing a formal body on child protection with a clearly defined mandate to monitor child protection in Eswatini and respond to specific issues when they arise.

- The schools should consider strengthening the teacherparent relationship so that all parties could work together to facilitate the management of the child's behavioural problem at an early stage.

\section{Acknowledgements}

We acknowledge all participants who took part in this study.

\section{Competing interests}

The authors have declared that no competing interests exist.

\section{Authors' contributions}

R.M. reviewed related literature and analysed the collected data and contributed to finding of the body of knowledge by adding more information in this area of study hence closing the geographical gap and the population gap. N.M. contributed by gathering data in the field.

\section{Funding information}

This research received no specific grant from any funding agency in the public, commercial, not-for-profit sectors, or for profit making.

\section{References}

Amato, P.R. \& Cheadle, J., 2008, 'Parental divorce, marital conflict and children's behaviour problems: A comparison of adopted and biological children', Social Forces 85(3), 1141-1161. https://doi.org/10.1353/sof.0.0025

Anyanwu, J. \& Obiyo, N.O., 2012, 'A survey of influence of home environment on academic achievement of children with emotional behavioural disorder (EBD)', Journal of the National Association of Exceptional Children 14(1), 114-124.

Babie, E., 2013, The practice of social research, Wadsworth, OH.

Bandura, A., 1977, Social learning theory, General Learning Press, New York, NY.

Belle, L.D., 2017, 'Factors that influence student behaviour in secondary schools', European Journal of Educational and Development Psychology 5(5), 27-36.

Binh, N.T., 2012, 'Role of family in educating-socializing children: The case of Vietnam', Current Research Journal of School of Social Sciences 4(2), 173-181.

Brewer, J.D., 2006, Ethnography, Sage, Philadelphia, PA.

Creswell, J.W., 2007, Research design: Qualitative, quantitative and mixed methods approaches, 3rd edn., Sage, London.

Creswell, J.W., 2011, Qualitative, quantitative, and mixed methods approach, Sage, Thousand Oaks, CA.

Creswell, J.W., 2014, Research design: Qualitative, quantitative, and mixed method approaches, 4th edn., Sage, Thousand Oaks, CA.

De Vos A.A., Strydom, H., Fourche, C.B. \& Delport, C.S.L., 2012, Research at grassroots: For the social sciences and human professions, 4th edn., Van Schaik Publishers, Cape Town. 
Denzin, N.K. \& Lincoln, Y.S., 2008, Strategies of qualitative inquiry, 3rd edn., SAGE, Thousand Oaks, CA.

Denzin, N. \& Lincolin, Y., 2011, The Sage handbook of qualitative research, 4th edn., Sage, New York, NY.

Dlamini, P., 2013, 'Factors responsible for maladaptive behaviour in high schools in the Manzini', unpublished Master's thesis, University of Swaziland, Swaziland.

Eyman, R.K. \& Call, T., 1977, 'Maladaptive behaviour and community placement of mentally restarted persons', American Journal of Deficiency 82(2), 137-144.

Florian, K., 2006, 'The use of qualitative content analysis in care study research', Qualitative Social Research Journal 7(1), 1-21.

Gasa, V.G., 2009, Learners aggressive behaviour in secondary schools, University of South Africa, Pretoria.

Henning, E., Van Rensburg, W. \& Smit, B., 2004, Finding your way in qualitative research, Van Schaik Publishers, Pretoria.

Huston, A.C., 1994, 'Children in poverty: Designing research to affect policy', Society for Research in Child Development 8(2), 1-16. https://doi.org/10.1002/j.2379 3988.1994.tb00030.x

Huston, A.C., 2003, Child in poverty. Child development and public policy, Cambridge University Press, New York, NY.

Huston, A.C., Mclyod, V.C. \& Coll, C.G., 2008, 'Children and poverty: Issues in contemporary research', Child Development 65(2), 275-715. https://doi. org/10.1111/j.1467-8624.1994.tb00750.x

Kwaja, P. \& Mormah, F.O., 2011, 'Managing adolescents' maladaptive behaviour in Nigeria secondary schools', Approaches in International Behaviour in Nigeria Secondary Schools 7(2), 128-145.

Mavundla, S., Dlamini, N., Nyoni, N. \& Mac-Ikemenjima, D., 2015, Youth \& public policy in Swaziland, Youth Policy Press, Berlin.

Mburugu, E.N. \& Adams, B.N., 2001, Families in Kenya, viewed 05 February 2019 from http://www.sagepub.com/upm.dat/4948.

Mburugu, E.N. \& Adams, B.N., 2005, 'Families in Kenya', in B.N. Adams \& J. Trest (eds.), Handbook of world families, SAGE. https://doi.org/10.4135/9781412975957.n1

Mcleod, S.A., 2011, Bandura-social learning theory, viewed 05 February 2019, from http://www.simplypsychology.org/bandura.html.

McMillan, J.H. \& Schumacher, S., 2010, Research in education: Evidence-based inquiry Pearson, New York, NY

Merriam, S.B., 2009, Qualitative research: A guide to design and implementation, John Wiley, San Francisco, CA.
Mhlongo, G.T., 2005, 'Drug abuse in adolescents in Swaziland', unpublished Master's thesis, University of South Africa, Pretoria.

Michubu, M.J., 2013, 'Socio-economic factors influencing students' academic performance in public secondary schools in Igembe South District, Kenya', Unpublished Masters thesis, Kenyatta University, Kenya.

Morehouse, R.E., 2011, Beginning interpretative inquiry, 1st edn. Imprint Routledge, London.

Mtonga, D.E., 2016, 'Abolishment of corporal punishment in Zambia: Evaluating alternative modes of discipline in selected government secondary schools in Lusaka District', unpublished Master's thesis, University of Zambia, Zambia.

Mweemba, G., 2011, 'Factors leading to deviant behaviours among pupils in selected high schools of Kabwe district', unpublished Master's thesis, University of Zambia, Lusaka.

Mwirichia, V.M., 2013, 'Influence of parental involvement on academic performance of preschool children in Kangeta Division, Meru County, Kenya', Unpublished Masters Thesis, University of Nairobi.

Nakpodia, E.D., 2012, 'Principals' attitudes towards corporal punishment in Nigerian secondary schools', Global Journal of Human Social Science Linguistics \& Education 12(11), 144-151.

Rhee, S.H. \& Waldman, I.D., 2009, 'Genetic and environmental influences on antisocial behavior: A meta-analysis of twin and adoption studies', Psychological Bulletin 128(3), 490-529. https://doi.org/10.1037/0033-2909.128.3.490

Rubin, K.H. \& Clark, M.L., 1983, 'Pre-school teachers' ratings of behavioural problems: Observational, sociometric, and social-cognitive correlates', Journal of Abnormal Child Psychology 6(4), 20-39.

Sarason, I.G., 2005, Abnormal psychology: The problem of Maladaptive behavior, 11th edn.

Spencer, I., Ritchie, J., Lewis, J. \& Dillion, L., 2003, Quality in qualitative evaluation: A framework for assessing research evidence, Routledge, London.

Sullivan, K., 2006, The anti-bullying handbook, 2nd edn., SAGE.

Tungata, M., 2006, Maintaining discipline in schools in the post-corporal punishment era, Nelson Mandela Metropolitan University, Port Elizabeth.

Ughamadu, K.A. \& Enueme, P.C., 2002, Sociology of education, Krisbec Publication, Agbor.

World Vision, 2018, Freedom House, Freedom in the World 2018 - Swaziland, 27 August 2018 , viewed 16 June 2020, from https://www.refworld.org/docid/5b8d24af26.html.

Zatto, B.R.L. \& Hoglund, W.L.G., 2019, 'Children's internalising problems and teacherchild relationship quality across pre-school', Early Childhood Research Quarterly 49(4), 28-39. https://doi.org/10.1016/j.ecresq.2019.05.007 